\title{
JURNAL MERPATI
}

Media Publikasi Pengabdian Kepada Masyarakat Politeknik Pos Indonesia https://ejurnal.poltekpos.ac.id/index.php/merpati

\section{SOSIALISASI PENGGUNAAN SIAP OPA BAGI KARYAWAN Balai Perlindungan Tanaman Pangan dan Hortikultura Provinsi Jawa Barat}

\author{
Roni Habibi ${ }^{1}$, Rolly Maulana Awangga ${ }^{2}$, Dinda Maesty ${ }^{3}$ \\ ${ }^{1}$ Teknik Informatika, Politeknik Pos Indonesia \\ ${ }^{1}$ ronihabibi@poltekpos.ac.id \\ 2 Teknik Informatika, Politeknik Pos Indonesia \\ 2awangga@poltekpos.ac.id \\ ${ }^{3}$ Teknik Informatika, Politeknik Pos Indonesia \\ 3.dindamesti@gmail.com
}

\begin{abstract}
ABSTRAK
Aplikasi SIAP OPA JABAR merupakan aplikasi berbasis android yang membantu karyawan dan staf yang bekerja di Balai Perlindungan Tanaman Pangan dan Hortikultura Provinsi Jawa Barat dalam melakukan pelaporan terkait dengan organisme pengganggu tanaman pangan (padi) di provinsi Jawa Barat. Aplikasi ini terdiri dari empat user yaitu POPT, Kortikab, Satuan Pelaksana, dan BPTPH. Cara kerja aplikasi ini yaitu dimulai dengan melakukan pengamatan terhadap tanaman padi sebanyak 30 rumpun padi, pengamatan ini dilakukan oleh POPT. POPT akan melaporkan hasil pengamatan hariannya dalam bentuk laporan harian POPT, POPT harus memilih salah satu OPT yang dianggap paling berbahaya bagi tanaman padi berdasarkan hasil pengolahan data pengamatan yang dilakukan pada hari tersebut. Laporan akan divalidasi oleh Kortikab, SatPel, dan BPTPH. Ketiga user ini berhak menolak laporan tersebut apabila terdapat kesalahan pada laporan yang dibuat oleh POPT dan memberikan komentar perbaikan untuk POPT, sehingga POPT dapat memperbaiki laporan. Hasil dari laporan akan diolah dan direkapitulasi menjadi laporan setengah bulan, laporan bulanan, dan laporan musiman. Setiap user dapat melihat data tersebut dalam maps dan chart yang ada pada aplikasi, data tersebut digunakan juga sebagai tindakan pencegahan agar kedepannya serangan hama dan penyakit pada tanaman padi dapat di cegah sebelum kerugian yang ditimbulkan semakin besar dan merugikan banyak pihak terutama para petani.

Aplikasi ini dibuat dengan menggunakan bahasa pemrograman java, framework code igniter, dan mysql database. Java digunakan untuk membuat aplikasi android SIAP OPA JABAR, framework code igniter digunakan untuk membuat dashboard dan API (sebagai backend), dan mysql digunakan sebagai database dari aplikasi ini. Pada sosialisasi ini akan disimulasikan cara kerja aplikasi mulai dari penginputan data dan pelaporan oleh POPT sampai dengan approval yang dilakukan oleh BPTPH dan melihat bagaimana hasil akhir dari data tersebut dan melihat laporan lengkap POPT yang telah di approve oleh BPTPH.
\end{abstract}

Kata Kunci: OPT, Java, Pengamatan, Pelaporan, Validasi, CI

\section{ABSTRACT}

The SIAP OPA JABAR application is an android-based application that helps employees and staff who work at the Center for the Protection of Food Crops and Horticulture of West Java Province in reporting related to food-disturbing organisms (rice) in West Java province. This application consists of four users, namely POPT, Kortikab, Implementing Unit, and BPTPH. The way this application works begins with observing 30 rice clumps of rice plants, this observation is carried out by POPT. POPT will report the 
results of its daily observations in the form of a POPT daily report, POPT must choose one of the pests that are considered the most dangerous for rice plants based on the results of observations made on that day. The report will be validated by Kortikab, SatPel, and BPTPH. The third user has the right to reject the report if there is an error in the report made by POPT and provide corrective comments for POPT, so that POPT can correct the report. The results of the reports will be processed and recapitulated into halfmonth reports, monthly reports, and seasonal reports. Each user can view the data in maps and charts in the application, the data is also used as a preventive measure so that future attacks of pests and diseases on plants can prevent losses before the losses incurred are getting bigger and harming many parties, especially farmers.

This application is made using the java programming language, codeigner framework, and mysql database. Java is used to create the SIAP OPA JABAR android application, the Igniter code framework is used to create the dashboard and API (as the backend), and mysql is used as the database of this application. In this socialization, it will simulate how the application works starting from data input and reporting by POPT to approval by $B P T P H$ and see how the final result of the data is and see the complete $P O P T$ report that has been approved by $B P T P H$.

Keywords: OPT, Java, approach, Reporting, Validation, CI

\section{PENDAHULUAN}

Perkembangan teknologi yang setiap hari terus berkembang dengan sangat pesat membuat berbagai bidang pekerjaan di dunia menjadi tertarik untuk menggunakan teknologi informasi sebagai perantara yang diharapkan dapat membantu mereka dalam melakukan pekerjaannya. Membuat pekerjaan yang berat menjadi terasa ringan, proses pekerjaan yang memakan waktu lama menjadi singkat, dan pekerjaan yang menghabiskan banyak tenaga serta biaya menjadi lebih mudah dan murah dengan adanya teknologi. Hal inilah yang dirasakan oleh Balai Perlindungan Tanaman Pangan dan Hortikultura Provinsi Jawa Barat (BPTPH).

Aplikasi SIAP OPA JABAR dibuat dengan tujuan mempermudah pekerjaan para karyawan dan staf dalam melakukan pengamatan dan pelaporan terhadap OPT (organisme pengganggu tumbuhan) pada tanaman pangan (padi) di Provinsi Jawa Barat. Tanpa aplikasi ini proses pengamatan dan pelaporan dilakukan secara manual sehingga membutuhkan banyak tenaga, waktu, serta biaya. Masalah lain yang ditemukan oleh para karyawan atau staf yaitu kesulitan dalam mengumpulkan data laporan dari tahun-tahun yang lalu, karena laporan masih berbasis kertas dan sangat rentan hilang ataupun rusak. Oleh karena itu dibuatlah sebuah sistem untuk memperbaiki proses manual yang saat ini sedang berjalan yang dapat mempercepat proses pengamatan dan pelaporan dan menyimpan data dengan jumlah yang banyak dan dalam jangka waktu yang lama. Aplikasi ini memiliki empat user yaitu POPT, Kortikab, SatPel, dan BPTPH. POPT bertugas dalam melakukan pengamatan terhadap tanaman dan melaporkan hasil pengamatannya kepada Kortikab yang dipegang oleh petugas Kabupaten tempat POPT berkerja. Kortikab merupakan petugas yang melakukan validasi terhadap laporan yang dikirimkan oleh POPT dan melaporkan kembali laporan yang telah ia validasi kepada Satuan Pelaksana yang bertugas pada Kabupaten yang sama dengan Kortikab. Satuan Pelaksana bertugas melakukan validasi terhadap laporan yang dikirimkan oleh Kortikab dan mengirimkan kembali laporan yang telah ia validasi kepada BPTPH (petugas provinsi).

Aplikasi ini dibuat menggunakan bahasa pemrograman Java dan berbasis android, menggunakan software android studio yang merupakan IDE untuk sistem operasi android sebagai media untuk membuat pengkodean aplikasi. Menggunakan bahasa pemrograman PHP dan framework CodeIgniter untuk membuat dashboard aplikasi serta membuat API untuk aplikasi android SIAP OPA JABAR. Sebagai media penyimpanan data aplikasi ini menggunakan MySQL database. Dashboard aplikasi ini dihosting menggunakan Hostinger dan dapat diakses dengan mengunjungi link https://siapopajabar.info/ dan aplikasi android SIAP OPA JABAR dapat didownload pada playstore dengan mengetikkan kata kunci siap opa.

ISSN (P): 2747-2345

E-ISSN (O): 2746-8704

MERPATI 3 (1) (2021) • Hal. 2 
Sebelum adanya aplikasi ini karyawan BPTPH melakukan pengamatan dan pelaporan secara manual yaitu dengan dating langsung ke kantor BPTPH membawa print dokumen laporan mereka setiap seminggu sekali. Dengan adanya aplikasi ini tentulah karyawan BPTPH akan dimudahkan dalam mengirimkan laporan via aplikasi dan laporanpun dapat dikirimkan setiap harinya. Namun dikarenakan aplikasi ini merupakan sesuatu hal yang baru bagi mereka dan kurangnya pengetahuan para karyawan mengenai teknologi maka dibutuhkan sosialisasi mengenai cara penggunaan aplikasi dan mensimulasikan aplikasi secara langsung bersama user. Sosialisasi ini dimulai dengan simulasi POPT yang menginputkan data dan melakukan pelaporan harian, kemudian laporan tersebut akan diterima oleh user Kortikab dan Kortikab akan melakukan approval pada laporan tersebut. Setelah itu, laporan akan diterima oleh SatPel dan SatPel akan mensimulasikan approval laporan. Terakhir laporan akan diterima oleh BPTPH dan di approve. Laporan yang telah di approve oleh BPTPH akan di rekap dan bisa dilihat dalam format excel. Setelah selesai acara sosialisasi maka akan dilanjutkan dengan tanya jawab mengenai aplikasi serta tanggapan dan saran dari user.

\section{METODE PELAKSANAAN}

\subsection{Pelaksanaan Kegiatan}

Waktu dan Tempat Penelitian

Waktu: April - November 2021

Tempat: Balai Perlindungan Tanaman Pangan dan Hortikultura Provinsi Jawa Barat

\subsection{Metode Pelaksanaan}

\subsubsection{Metode Pendekatan}

Menggunakan metode pendekatan sosialisasi dengan tujuan untuk memberikan gambaran mengenai aplikasi yang akan digunakan oleh karyawan BPTPH dan memudahkan mereka dalam memahami cara kerja atau alur dari aplikasi. Sosialisasi ini merupakan proses belajar bagi para karyawan BPTPH agar dapat memahami dan terbiasa dalam menggunakan aplikasi dan teknologi yang baru dan asing bagi mereka.

Mengadakan sosialisasi atau penyuluhan mengenai cara penggunaan aplikasi dan mensimulasikan aplikasi secara langsung bersama user. Sosialisasi ini dimulai dengan simulasi POPT yang menginputkan data dan melakukan pelaporan harian, kemudian laporan tersebut akan diterima oleh user Kortikab dan Kortikab akan melakukan approval pada laporan tersebut. Setelah itu, laporan akan diterima oleh SatPel dan SatPel akan mensimulasikan approval laporan. Terakhir laporan akan diterima oleh BPTPH dan di approve. Laporan yang telah di approve oleh BPTPH akan di rekap dan bisa dilihat dalam format excel. Setelah selesai acara sosialisasi maka akan dilanjutkan dengan tanya jawab mengenai aplikasi serta tanggapan dan saran dari user.

\subsubsection{Tahapan Pelaksanaan:}

a. Pembukaan

Membuka acara dengan mengenalkan aplikasi ini kepada para user.

b. Simulasi

Melakukan simulasi aplikasi dengan para user secara langsung.

c. Tanya Jawab

Tanya jawab antara user dengan developer mengenai aplikasi.

d. Kritikan dan Saran

User memberikan tanggapan terhadap aplikasi, jika terdapat bug, eror, dan segala macam yang membuat user tidak nyaman

e. Perbaikan

Developer akan memperbaiki aplikasi dan menyesuaikan aplikasi dengan keinginan user.

f. Simulasi Perbaikan

Melakukan simulasi ke dua dengan aplikasi yang telah disesuaikan dengan keinginan user.

\subsection{Solusi Permasalahan}

Solusi dari permasalahan yang dihadapi oleh karyawan BPTPH karena sedikitnya pengetahuan mengenai teknologi dan cara penggunaan aplikasi android serta web maka diadakan sosialisasi untuk memberikan ISSN (P): 2747-2345

E-ISSN (O): 2746-8704

MERPATI 3 (1) (2021) • Hal. 3 
pemahaman kepada para karyawan BPTPH.

\section{HASIL DAN PEMBAHASAN}

Kegiatan dimulai dengan presentasi dari developer aplikasi mengenai teknologi apa saja yang digunakan kemudian memperlihatkan fitur-fitur aplikasi kepada user. Kemudian dilanjutkan dengan simulasi, pada tahap simulasi 100 orang user POPT berpartisipasi dan melakukan simulasi penginputan data serta pembuatan laporan harian. Setelah proses simulasi laporan harian dilakukan terdapat beberapa eror atau bug. Simulasi dihentikan sementara dan developer melakukan perbaikan aplikasi. Setelah selesai perbaikan simulasi dilanjutkan dengan pelaporan laporan harian kepada user kortikab, satpel, dan bptph yang diujicobakan oleh 4 orang user kortikab, satpel dan 2 orang user bptph. Setelah simulasi beberapa orang user bertanya terkait tata cara penggunaan aplikasi serta memberikan kritikan dan saran sehingga developer perlu melakukan perbaikan terhadap aplikasi sesuai dengan saran yang diberikan oleh user. Setelah aplikasi disesuaikan dengan saran user maka user kembali melakukan simulasi terhadap aplikasi yang baru.

Kegiatan ini menghasilkan beberapa revisi terhadap aplikasi dari user seperti POPT, Kortikab, Satpel, dan BPTPH. Revisi dari user sudah dikerjakan sehingga menghasilkan aplikasi yang saat ini sudah bisa digunakan oleh user. Beberapa revisi tersebut yaitu eror saat set lokasi gps dan penginputan yang lama dikarenakan input foto yang terlalu banyak, serta perbaikan pada tampilan aplikasi agar user lebih mudah memahami aplikasi. Selain aplikasi android kami juga menyediakan dashboard berupa web untuk user agar lebih mudah mengakses data-data pengamatan dan laporan pengamatannya serta memudahkan admin dalam memantau user aplikasi.

Dampak diadakannya PKM ini sangat banyak, diantaranya:

a. User yang sebelumnya tidak mengerti cara menggunakan aplikasi menjadi mengerti cara penggunaannya.

b. Aplikasi yang sebelumnya memiliki banyak eror seperti eror versi android, lokasi gps, dan penginputan foto menjadi dapat diketahui erornya dan dapat diperbaiki berkat uji coba yang dilakukan user.

c. User dapat memberikan saran dan masukan untuk tampilan aplikasi sehingga membuat user menjadi lebih nyaman dalam menggunakan aplikasi.

Berikut tampilan aplikasi android siap opa:

Pada Tampilan Beranda terdapat informasi user dan notifikasi approval laporan pengamatan serta terdapat laporan berbentuk chart dan peta penyebaran organisme pengganggu tanaman.
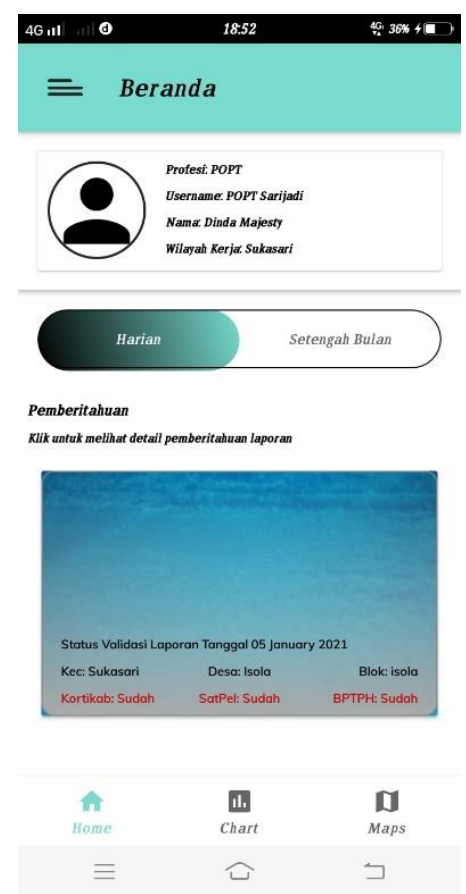

ISSN (P): 2747-2345

Gambar 1. Menu Beranda Aplikasi Siap OPA
E-ISSN (O): 2746-8704
MERPATI 3 (1) (2021) • Hal. 4 
Pada tampilan menu terdapat berbagai menu seperti harian keliling yang berguna untuk POPT melakukan pengamatan harian keliling dari satu desa ke desa lainnya. menu harian digunakan untuk membuat laporan pengamatan harian, Menu setengah bulan untuk laporan setengah bulan, menu bulanan untuk laporan bulanan, menu musiman untuk laporan musiman terdiri dari musim kemarau dan musim hujan.

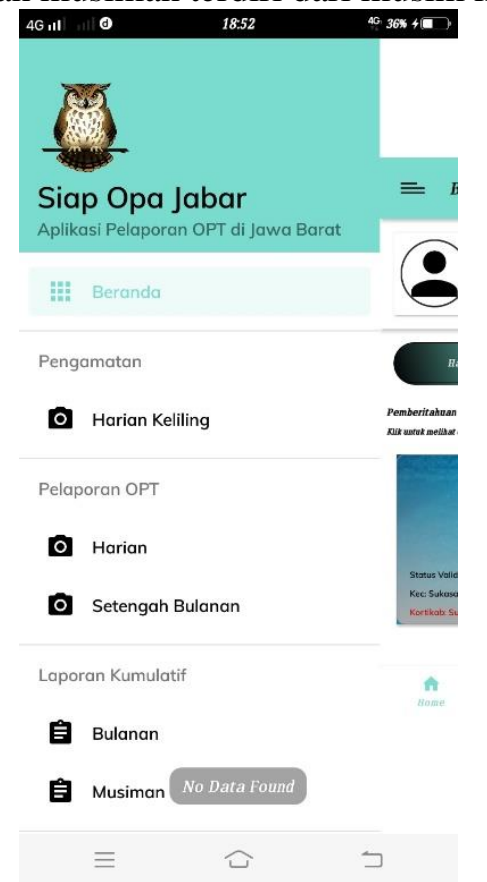

Gambar 2. Menu Aplikasi Siap OPA

Pada Dashboard menu-menu lebih lengkap terutama dashboard admin karena pada dashboard admin segala akses ke database dibuatkan tampilan pada dashboardnya, sehingga memudahkan admin dalam melakukan penyetingan pada database.

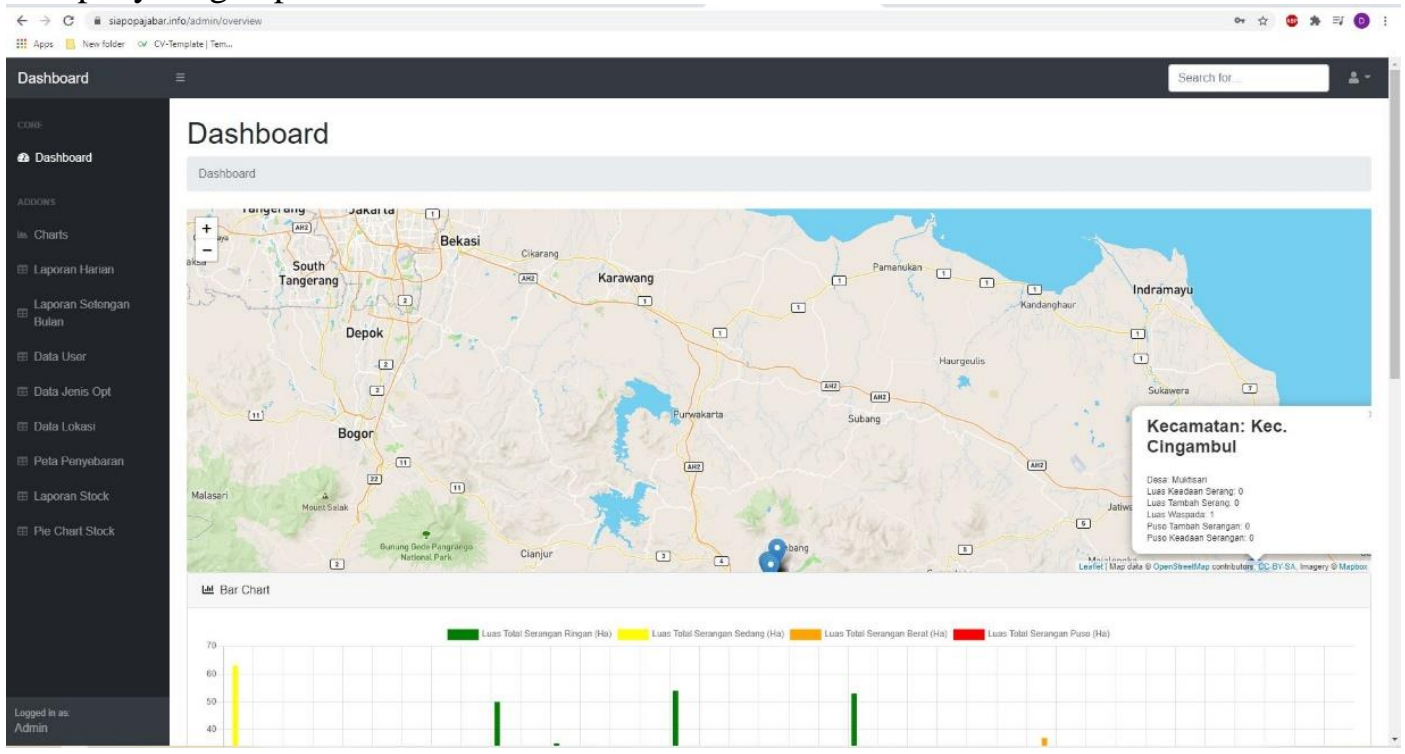

Gambar 3. Dashboard Siap OPA

Pembuatan implementasi dari Aplikasi Siap Opa membutuhkan hal-hal sebagai berikut:

1. Hosting, merupakan layanan yang menyimpan data website agar dapat diakses melalui internet. Hosting yang digunakan dalam pembuatan aplikasi ini yaitu Hostinger. Spesifikasi server sebagai berikut:

a. Unlimited Bandwidth

b. $\quad 140$ GB SSD Storage

c. 6 GB RAM

d. 4 CPU Core

ISSN (P): 2747-2345 


\section{e. $\quad 2 x$ Speed Boost}

2. Domain, merupakan nama unik yang digunakan untuk mengidentifikasi nama server komputer seperti web server di internet. Domain yang digunakan yaitu .info.

3. SSL (Secure Socket Layer), merupakan protokol kriptografi yang dirancang untuk memberikan keamanan komunikasi melalui jaringan komputer sehingga website menjadi lebih aman untuk diakses.

4. REST API, merupakan penghubung komunikasi antara website dengan aplikasi android, dibuat dengan menggunakan framework CodeIgniter 3.

5. MySQL, berfungsi sebagai penyimpanan data pada aplikasi ini.

6. Java, merupakan bahasa pemrograman yang digunakan dalam pembuatan aplikasi android.

7. Android Studio, IDE yang digunakan untuk membuat pengkodean program.

8. Perangkat Android minimal versi Android 6.

Implementasi sistem berjalan dengan baik dan memberikan hasil yang memuaskan. Sistem yang telah dibuat dapat menyelesaikan permasalahan yang dihadapi oleh user yaang menginginkan sebuah sistem berbasis android yang dapat memudahkan user POPT dalam menginputkan data dan mengolah data pengamatan serta melakukan pelaporan OPT berdasarkan hasil pengamatan tersebut.

Berikut cara sistem ini menyelesaikan masalah pengamatan dan pengolahan data pengamatan POPT:

1. POPT dapat menginputkan data pengamatan seperti tanaman, lokasi pengamatan, luas tanaman, luas yang diamati, dll.

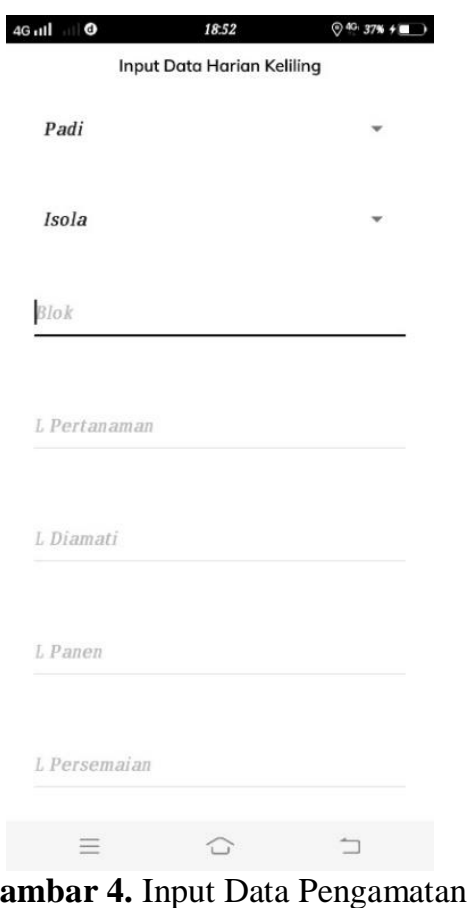

2. POPT dapat melihat hasil yang telah diinputkannya serta hasil pengolahan data pengamatan melalui PDF file untuk melakukan pengecekan data dan pemeriksaan kembali data sebelum disimpan. 

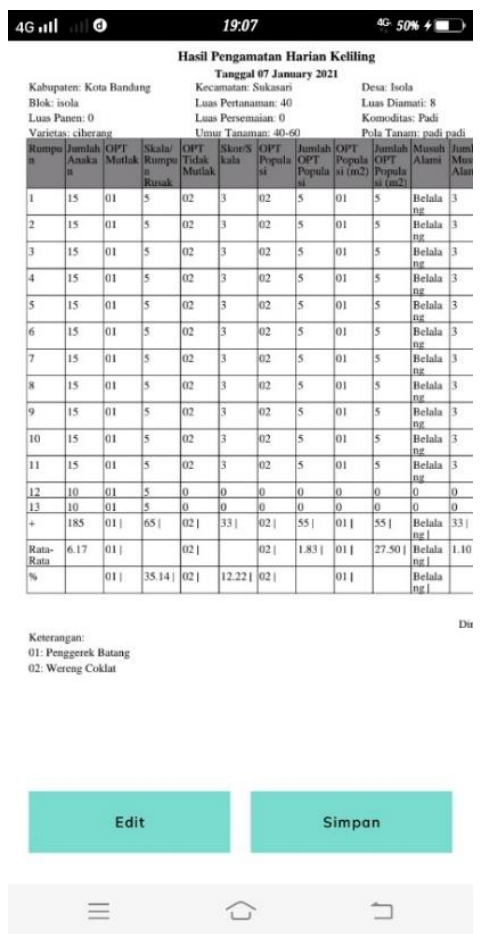

Gambar 5. Hasil Pengamatan

3. Hasil pengamatan dan detail pengamatan dapat dilihat oleh POPT melalui aplikasi android mereka.

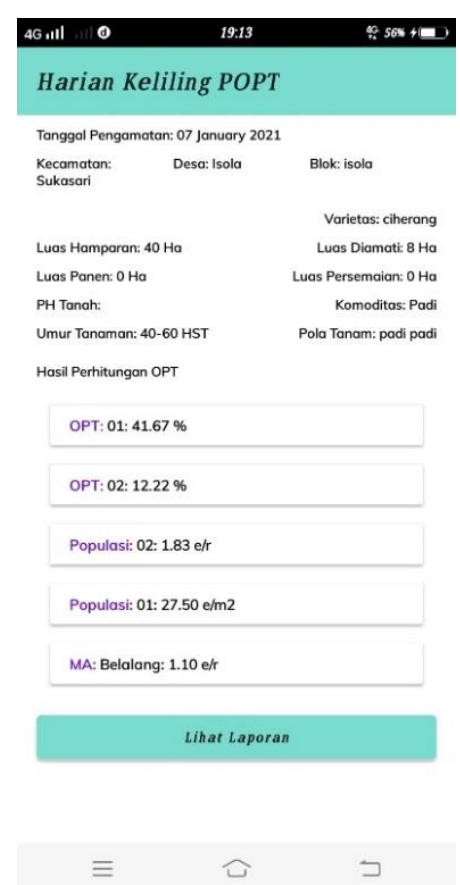

Gambar 6. Detail Hasil Pengamatan

Selain masalah pengamatan, aplikasi ini juga menyelesaikan masalah pelaporan OPT dengan menggunakan aplikasi android yang sama, pada menu Harian. Berikut cara sistem ini menyelesaikan masalah pelaporan OPT:

1. POPT membuka menu Harian.

2. POPT memilih salah satu OPT untuk dilaporkan dan menginputkan rekomendasi pengendalian untuk kerusakan yang disebabkan oleh OPT yang dipilih.

3. POPT klik laporkan, maka laporan harian format PDF akan dibuatkan otomatis oleh aplikasi.

4. Kortikab, SatPel, BPTPH login dan memilih menu validasi harian, kemudian pilih laporan yang 
akan di validasi.

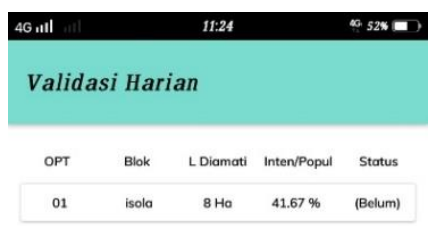

Gambar 7. Validasi Laporan Harian

5. Muncul tampilan detail laporan yang akan di validasi. Korikab, SatPel, BPTPH memeriksa laporan tersebut dan memberikan catatan untuk popt.

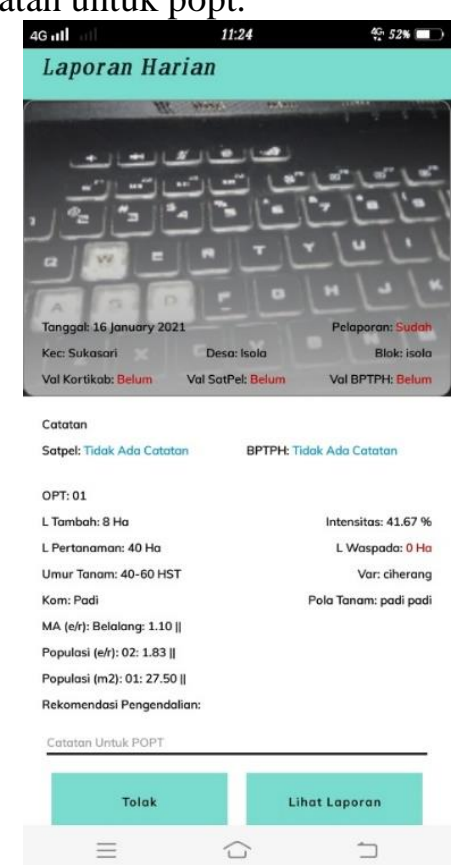

Gambar 8. Detail Validasi Laporan

6. Korikab, SatPel, BPTPH klik lihat laporan untuk melihat laporan Pdf yang telah dibuat dan dikirimkan oleh POPT. 

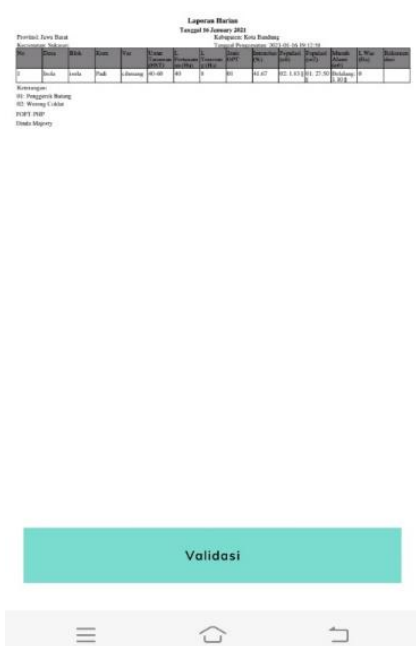

Gambar 9. Tampilan PDF laporan Harian

7. Korikab, SatPel, BPTPH klik validasi dan status validasi laporan akan berubah dari belum menjadi sudah.

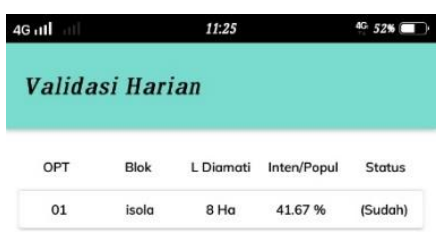

Gambar 10. Validasi Laporan Sukses

Masalah lainnya yaitu menyimpan data dengan rapi dan terstruktur, agar mudah dicari ketika data dibutuhkan. Masalah ini dapat diselesaikan oleh sistem yaitu dengan membuat database dengan menggunakan MySQL dan data tersebut ditampilkan pada dashboard, sehingga ketika data-data dibutuhkan maka user hanya perlu membuka dashboard dan login menggunakan username dan password yang sama dengan aplikasi android. Berikut tampilan dashboard untuk melihat data-data rekapan laporan harian dan setengah bulan. 


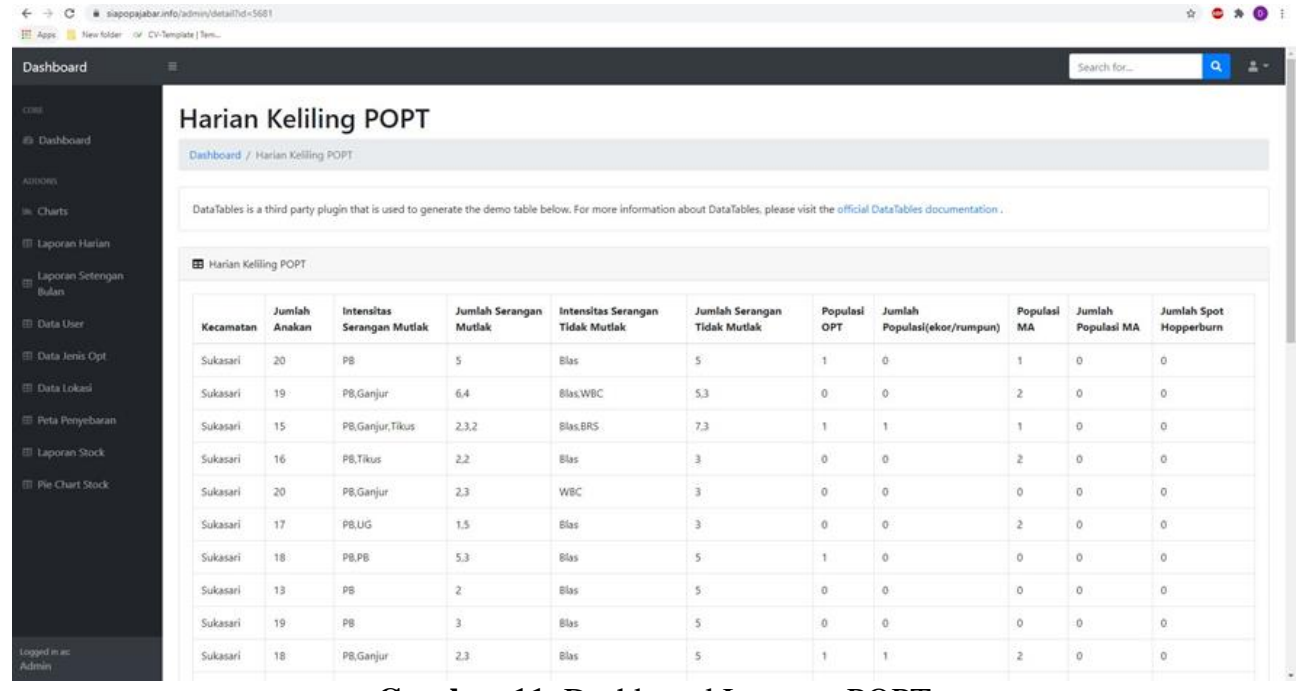

Gambar 11. Dashboard Laporan POPT

Kemanfaatan Fungsi Aplikasi terhadap Permasalahan:

1. POPT menjadi lebih mudah dalam melakukan pengamatan harian dan pengolahan datanya, tanpa sistem/aplikasi proses pengamatan dan pengolahan data berlangsung lama (lebih dari satu hari).

2. $\quad$ POPT menjadi lebih mudah dalam membuat laporan harian yang akan dilaporkan kepada Kortikab, SatPel, dan BPTPH. dengan adanya sistem proses ini berlangsung satu hari kerja, sedangkan tanpa sistem pelaporan oleh POPT dan validasi oleh Kortikab, SatPel, dan BPTPG dilakukan selama setengah bulan.

3. Data-data laporan dan pengamatan tersusun rapi dan data tidak mudah rusak atau hilang, karena sebelum menggunakan sistem laporan akan di print dan sangat mudah robek, rusak, dan hilang.

4. Pembuatan rekap data dalam bentuk chart, maps, dan tabel menjadi sangat mudah, awalnya dilakukan oleh seorang karyawan, tetapi dengan adanya sistem rekapan tersebut dibuat otomatis apabila laporan telah di validasi oleh BPTPH.

Aplikasi ini telah diuji dengan cara trial and eror, aplikasi tersedia di google play store dapat diunduh dan diujicobakan langsung oleh user. Uji coba aplikasi sudah dilakukan dengan mendatangkan 60 peserta dan bertindak sebagai POPT, Kortikab, SatPel, dan BPTPH.

skema pengujian aplikasi sebagai berikut:

1. POPT login aplikasi dengan memasukkan username dan password, tidak ada keluhan dalam proses login, proses ini berjalan dengan lancar tanpa ada eror program.

2. POPT memilih menu harian keliling untuk menambahkan data pengamatan, menginputkan data umum, bukti foto, data rumpun, dan data opt. Beberapa user mengeluh error karena proses insert data yang terlalu lama, hal ini disebabkan karena koneksi internet dan penyebab lainnya yaitu akses gps pada aplikasi tidak bekerja dengan baik di semua versi android, versi yang mengalami masalah yaitu versi android 10. Eror ini sudah diperbaiki dengan menggunakan Google Location API, menambahkan function updateLocation, dan menambahkan izin akses gps (high accuracy) sehingga proses ini menjadi lebih cepat. Berikut gambaran izin akses gps: 


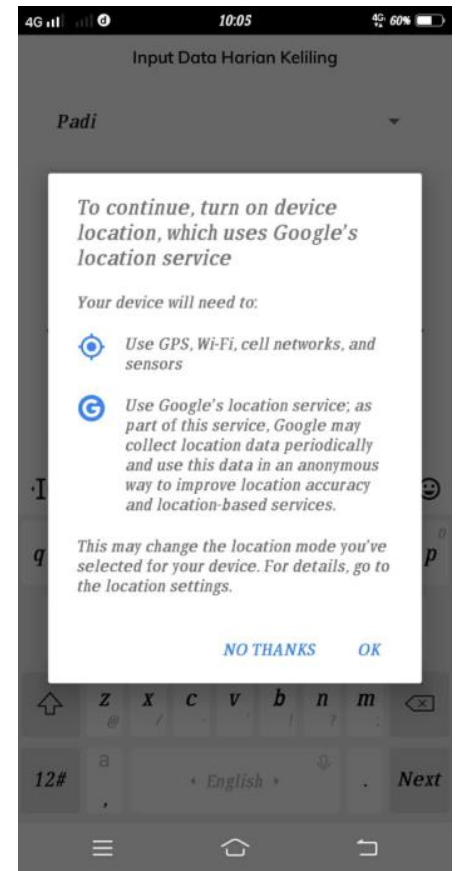

Gambar 12. Izin Aplikasi untuk Menggunakan Lokasi Perangkat

3. POPT memilih menu harian untuk membuat laporan harian, memilih salah satu OPT untuk dilaporkan, dan memberikan rekomendasi pengendalian. POPT klik tombol laporkan untuk melaporkan opt tersebut dan laporan akan diterima oleh Kortikab. Proses ini berjalan dengan baik tanpa ada eror atau bug yang ditemukan. Berikut output dari proses ini:

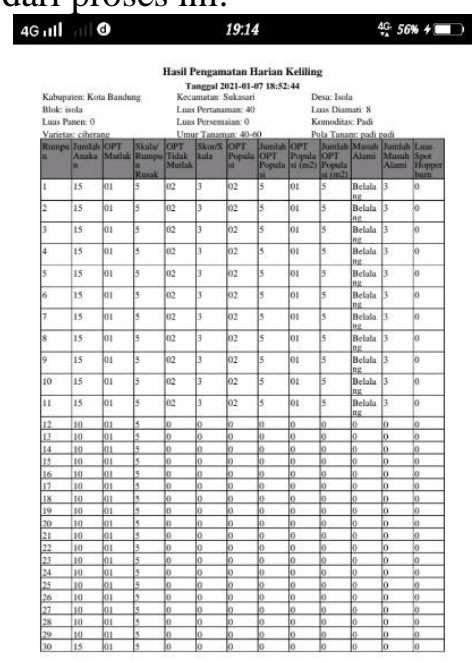

Gambar 13. Tampilan PDF Hasil Pengamatan 30 Rumpun

4. Login dan memilih menu validasi harian, membuka laporan dan melihat detail laporan serta melakukan pemeriksaan pada laporan. Kortikab klik button tolak untuk menolak laporan dan memberikan alasan penolakan, atau Kortikab klik tombol validasi untuk memvalidasi dan memberikan komentar atau tanggapannya kepada POPT. Proses ini berjalan dengan baik. Outputnya yaitu status validasi laporan yang berubah menjadi sudah

5. Laporan yang divalidasi oleh Kortikab akan diterima oleh SatPel, selanjutnya SatPel melakukan 
hal yang sama seperti kortikab, proses ini berjalan dengan baik.

6. Selanjutnya laporan diterima oleh user BPTPH, BPTPH melakukan validasi seperti user kortikab sebelumnya, proses ini berjalan dengan baik, dan user POPT menerima info atau pemberitahuan bahwa laporannya telah berhasil divalidasi.

\section{KESIMPULAN}

Dengan diadakannya sosialisasi ini maka karyawan BPTPH yang awalnya tidak memahami teknologi dan tata cara penggunaan aplikasi dapay memahami dengan baik tentang teknologi yang digunakan dalam aplikasi ini serta tata cara penggunaan aplikasi, bahkan beberapa dari mereka memberikan kritikan dan saran yang lebih baik agar aplikasi ini lebih mudah untuk mereka gunakan. Beberapa perbaikan yang disarankan oleh user diantaranya mengenai eror penginputan foto dan eror ketika membaca titik kordinat user, beberapa versi android user tidak mendukung metode ini, developer telah memperbaiki eror ini agar lokasi user dapat terdeteksi dengan baik. Dengan adanya saran dari user aplikasi inipun menjadi lebih bagus dan user-friendly sehingga menimbulkan kenyamanan ketika digunakan. Hal ini tentunya tidak akan tercapai tanpa adanya sosialisasi ini.

\section{REFERENSI}

[1] A. Belkhir, M. Abdellatif, R. Tighilt, N. Moha, Y. G. Gu'eh'eneuc, and E. Beaudry. ' An observational study on the state of rest api uses in android mobile applications. In 2019 IEEE/ACM 6th International Conference on Mobile Software Engineering and Systems (MOBILESoft), pages 66-75, 2019.

[2] Kementrian Pertanian Direktorat Perlindungan Tanaman Pangan, direktorat Jendral Tanaman Pangan. Petunjuk Teknik Pengamatan dan Pelaporan Organisme Pengganggu Tumbuhan dan Dampak Perubahan Iklim (OPT-DPI). 2018.

[3] R. V. Golhar, P. A. Vyawahare, P. H. Borghare, and A. Manusmare. Design and implementation of android base mobile app for an institute. In 2016 International Conference on Electrical, Electronics, and Optimization Techniques (ICEEOT), pages 3660-3663, 2016.

[4] M. R. Regitha, N. Antony, S. Sivan, and V. Paul. Optimization of handoff delay and location prediction of mobile station using gps integrated sim module in cellular networks. In 2017 International Conference on Intelligent Computing, Instrumentation and Control Technologies (ICICICT), pages 582587, 2017.

[5] K. Saputra, K. Farhan, and I. Irvanizam. Analysis on the comparison of retrofit and volley libraries on android-based mosque application. In 2018 International Conference on Electrical Engineering and Informatics (ICELTICs), pages 117-121, 2018.

[6] A. Sarkar, A. Goyal, D. Hicks, D. Sarkar, and S. Hazra. Android application development: A brief overview of android platforms and evolution of security systems. In 2019 Third International conference on I-SMAC (IoT in Social, Mobile, Analytics and Cloud) (I-SMAC), pages 73-79, 2019. V-46

[7] R. D. H. Tobing. Mobile tourism application for samosir regency on android platform. In 2015 International Symposium on Technology Management and Emerging Technologies (ISTMET), pages 249-253, 2015.

[8] S. Tongkaw and A. Tongkaw. A comparison of database performance of mariadb and mysql with oltp workload. In 2016 IEEE Conference on Open Systems (ICOS), pages 117-119, 2016. 